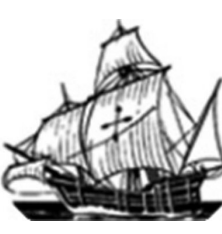

\title{
Inserção da linguagem poética oral - uma aposta no rap como prática pedagógica
}

\author{
Fabiana Aparecida de Melo Oliveira (Abdim) ${ }^{1}$ \\ Laís Pereira Leonel da Silva (Abdim/USP)²
}

\section{Resumo}

Este relato de experiência tem por finalidade abordar a inserção da linguagem poética em aulas voltadas a alunos com necessidades educacionais especiais. Trata-se da problematização de ações pedagógicas realizadas em um cenário distinto da escola regular, haja vista que foram empreendidas no Programa de Atendimento Escolar ao Aluno da Associação Brasileira de Distrofia Muscular. Toma-se como objeto um conjunto de ações produzidas junto a um jovem de 18 anos, negro, não alfabetizado, afetado por distrofia muscular de Duchenne. Nesse contexto, ressaltamos o emprego do rap como recurso favorável à aquisição de maiores possibilidades de problematizar o mundo e aguçar o olhar crítico do indivíduo, bem como meio facilitador do trabalho vinculado ao campo da expressividade, elemento extremamente importante frente a alunos com uma trajetória e percurso formativo tão singular como o são os atendidos pelo Programa de Atendimento Escolar ora evidenciado. Por fim, acreditamos que o emprego do rap também se mostra absolutamente válido nos outros tantos cenários em que o ensino de Literatura se faz presente, principalmente nas escolas regulares.

Palavras-chave: Rap. Oralidade. Distrofia Muscular de Duchenne.

\footnotetext{
Abstract: This experience report has the purpose to broach the insertion of the poetry vocabulary in lectures for special needs students. It's about the problematization of the pedagogic

1 Professora Mestre na Área de Concentração: Educação, Conhecimento, Linguagem e Arte, pela Universidade Estadual de Campinas. Coordenadora Pedagógica do Programa de Atendimento Escolar ao aluno da Associação Brasileira de Distrofia Muscular (Abdim).

2 Graduanda em Letras pela Faculdade de Filosofia Letras e Ciências Humanas da Universidade de São Paulo (FFLCH - USP). Professora Aprimoranda na área de Ciências Humanas na Associação Brasileira de Distrofia muscular (Abdim).
} 
activities, performed on a different scenario of the 'Regular' school, once they were undertake on the 'Scholastic attending Program to the Student of Associacão Brasileira de Distrofia Muscular'. From the set of lectures undertake which, in the case of the present narrative of experience, are centered on actions developed with a 18-year old man, African-American, nonliterate, affected by Duchenne's Muscular Dystrophy, we emphasize the use of rap as a favorable resource to the acquisition of more possibilities to analyze the world and sharpen one's critical examination, as well as enabler of the work bounded to the agressiveness, a extremely important element to students with a formative path as unique as the staff attended by the Scholastic Attending Program, sometimes evident. Finally, we believe that the use of rap turns absolutely valid on other scenarios in which the literature is present, especially on the 'regular schools'.

Keywords: Oral poetry. Rap. Muscular Dystrophy.

"E o rótulo, quando necessário, deve ser usado, sim, mas como estratégia de afirmação da diferença, sem se constituir num grilhão." Nei Lopes

\section{Para entender o lócus de ensino e delimitar a ação pedagógica abordada}

Por meio deste relato de experiência, almejamos problematizar questões relacionadas ao emprego de poéticas orais nas aulas de Literatura, considerando, assim, o debate que tem movimentado a área de ensino nesse campo. Por nossa ação estar centrada em um cenário distinto da escola regular, consideramos também o desafio do ensino na área de Linguagens voltado a alunos com necessidades educacionais especiais.

O lócus em que ação pedagógica em destaque foi empreendida remete à Associação Brasileira de Distrofia Muscular (Abdim), instituição recentemente incorporada pela Associação de Assistência à Criança Deficiente (AACD), ambas sediadas na cidade de São Paulo.

Distrofia Muscular é um grupo de doenças, formada, na realidade, por mais de 30 tipos de patologias. Dentre as várias patologias que compõem o grupo, ressaltamos a distrofia de Duchenne, por ser a de maior incidência na população e por seu expressivo impacto no desenvolvimento neuropsicomotor. Caracteriza-se como uma doença progressiva, que incide 
sobre músculos esqueléticos, coração e cérebro, afetando um em cada 3.600 a 6.000 meninos. A doença se manifesta na infância, por volta dos 3-4 anos e leva à perda total dos movimentos inferiores aproximadamente entre os 11-12 anos. Assim como os danos relacionados aos movimentos, há também impacto referente ao desenvolvimento cognitivo (Nardes, 2011). Memória de curto prazo e habilidades relacionadas ao domínio verbal tendem a ser impactadas em porcentagem expressiva daqueles que são afetados por tal distrofia, aspecto que incide diretamente no campo da aprendizagem. Além disso, há que se mencionar o desafio de elementos atrelados à acessibilidade e a dependência de auxiliares de vida diária, aspectos que repercutem diretamente na rotina escolar e revelam parte do cenário de adversidades que esses alunos enfrentam.

Cabe ressaltar também o percurso formativo da população da Abdim, uma vez que este relato está centrado em práticas pedagógicas empreendidas pelo Programa de Atendimento Escolar em vigência em tal cenário. Grande parte dos discentes não está matriculada em nenhuma instituição regular de ensino e metade do grupo de alunos matriculados não é alfabetizado, embora não se trate de alunos matriculados nas séries iniciais do Ensino Fundamental I.

Dentre os alunos em atendimento, faz-se necessário evidenciar $\mathrm{RLR}^{3}$, inspirador deste trabalho, junto a quem as ações aqui propostas foram colocadas em prática. RLR é um aluno de 18 anos, negro, não alfabetizado, vítima de abandono familiar, já apresentando impactos expressivos do avanço da distrofia, como perda total da marcha. Além disso, como parcela significativa dos alunos afetados pela Distrofia Muscular de Duchenne, RLR apresenta prejuízos significativos no tocante ao desenvolvimento cognitivo. Seu histórico escolar é absolutamente fragmentado. Ele mesmo não sabe até que série cursou e, tampouco, quantas vezes foi reprovado. Menciona, no entanto, que apesar de não querer se matricular em uma escola da rede oficial, tem muita vontade de aprender a ler e escrever.

De acordo com as perspectivas apontadas, almejamos trazer à tona uma reflexão sobre os desafios do ensino na área de Linguagens priorizando questões inerentes ao ensino de Literatura e buscando refletir sobre os alcances e possibilidades do uso do rap nas aulas. Nesse sentido, valorizamos a importância de considerar os gostos, interesses e repertório do aluno, bem como o rap como um canal de diálogo e aproximação entre professor e discente. Para tanto, privilegiamos uma reflexão sobre o conceito e ensino de Literatura, enfatizando a

3 Com o intuito de preservar a identidade do aluno usaremos, ao longo do trabalho, apenas a abreviatura de seu nome. 
importância da oralidade em tal contexto e o uso de rap, potencializando sua significação enquanto produção poética. Assim, exploramos o rap como uma legítima expressão artística, centrada na oralidade, e defendemos sua inserção em ações pedagógicas, valorizando seu contexto de produção e esferas de circulação, bem como considerando-o como um elemento disparador, construtor e veiculador de conhecimento.

\title{
Contextualizando e localizando o lugar do rap entre as poéticas orais
}

Para iniciar nossos estudos cabe um breve resumo da história do rap, a fim de situá-lo no contexto social contemporâneo, sem perder de vista sua origem, bem como sua variação, recurso que lhe permitiu assumir novas matizes, ao longo do tempo.

O rap nasceu nos EUA, em meados da década de 70, constituindo-se como um elemento do movimento Hip-Hop, sendo os outros o grafite e o break (dança). Conquistou espaço no Brasil nos anos 80, atingindo, principalmente, as zonas periféricas. Segundo Bentes, Fernandes (2007) as siglas de rap constituem uma abreviatura de rithm and poetry, na língua inglesa.

No Brasil, por sua vez, o rap vem sendo interpretado como sinônimo de “compromisso". Esse é , por exemplo, o jargão criado por Sabotage, rapper bastante reconhecido, sobretudo, no cenário paulistano e foi responsável por forjar, não apenas tal expressão, mas também um modo bastante autêntico de se conceber a função social do rap entre os próprios rappers e seus intercolutores diretos.

\begin{abstract}
Mas não é apenas como um gênero musical que o hip-hop se manisfesta e pode ser definido. Sua linguagem poética é variada e apresenta uma mescla de grafite (com desenhos de protesto ou de marcas de território de guangues ou ainda com frases de impacto), com a moda (caracterizada pelo estilo próprio se ser vestir: camisetas longas, calças folgadas e bonés) e o verso ácido (identificado pelas redondilhas de rimas irregulares na voz de quem acompanha a batida ou pelo verso de improviso feito na disputa free style)." (BENTES, FERNANDES, 2007, p.125).
\end{abstract}

É evidente que não é apenas uma alcunha ou o desdobramento das letras que definem o caráter de um elemento, quiçá de uma manifestação artística imbuída de tantas facetas. Assim, pode-se perceber que o rap é manifestação poética oral do movimento Hip-Hop e integra, portanto, a dimensão da poeticidade na fala, no gesto, no tom, como ocorre com a a essência cordel ou mesmo do cururu, embora em um viés urbano, associado ao caráter 
geralmente revoltoso e indócil de grupos marginalizados.

Nesse sentido, apoiamo-nos na contribuição de Fernandes, que ressalta o rap como"uma poética feita no e para um determinado segmento social" (Fernandes, 2007, p. 126). A partir dessa perspectiva, podemos identificar os jovens, em geral afrodescendentes, moradores de comunidades e outros recantos de periferias, como grupo que produz e consome tal manifestação artística. Cabe ressaltarmos que as letras têm por origem, a exemplo do contexto histórico em que nasceram - segregação racial vigente nos anos 60 nos EUA - , forte teor crítico e são impregnadas de revolta, denúncia e ideologia frente às questões político-sociais. Posto isto, é possível compreender o rap como um encontro entre ética e estética, como uma poética ideológica, uma vez que abarca questões de lutas sociais e posicionamentos políticos dentro de um grupo específico.

\footnotetext{
A identidade do hip-hop está profundamente arraigada à experiência local e específica e ao apego a um status em um grupo local ou familiar, forjada a partir de um vínculo intercultural que, a exemplo das formações de guangues, promovem isolamento e segurança em um ambiente complexo e inflexível. E de fato, contribuem para a construção das redes comunidade que servem para os novos movimentos socias". (ROSE, 1997, apud BENTES, FERNANDES, 2007)
}

Cabe frisar que, como afirmado anteriormente, o rap se deu sob os alicerces de "grupos fechados" e, marcadamente, marginalizados, embora ao longo do tempo tenha assumido outras posições, fazendo com que o cenário atual seja bem diverso. Os principais rappers da cena brasileira não limitam suas vozes, e, por conseguinte, suas ideias, aos interlocutores da periferia. O rap vem assumindo outras esferas da sociedade. Hoje é, acima de tudo, vendável e incorpora interlocutores entre a classe média e alta.

Ainda tomando como referência a contribuição de Bentes e Fernandes (2007), ressaltamos que o movimento Hip-hop, e, por consequência, o próprio rap, deve ser entendido como "uma antropofagia capaz de assimilar, traduzir e recriar, fruto de um diálogo sem fronteiras raciais ou regionais, que faz com que o hip-hop encontre receptores e admiradores para além dos bairros periféricos.”(Ibidem, p. 131)

A breve contextualização do movimento Hip-hop, feita até aqui, tem por objetivo identificar o rap como partícipe ativo de uma cultura, bem como uma legítima poética da voz

\section{Repensando o valor das poéticas orais em sala de aula}


Outro aspecto importante, que tomará espaço nesse trabalho, é o processo de revalorização da oralidade dentro da sala de aula, permitindo-nos empreender as práticas aqui relatas.

A valorização da oralidade em um ambiente historicamente de supremacia da escrita, isto é, nas aulas de Linguagens, é uma premissa que temos buscado colocar em prática ao longo de nossas ações pedagógicas. Tomamos como referência o debate acerca do tema, haja vista que nos últimos anos muitos pesquisadores têm contribuído para o rompimento da dicotomia oralidade versus escrita (Marcuschi, 2001; Castilho, 2000; Fávero, Andrade, Aquino, 1999). Além de uma gama de publicações oriundas de pesquiadores das áreas de Letras, consideramos diretrizes da educação em nosso país, como os Parâmetros Curriculares Nacionais (2000), por exemplo.

A respeito da busca pelo rompimento com a supremacia da escrita nas aulas de Liguagens, parece-nos válido ressaltar a representação que muitos dos próprios discentes atendidos no Programa de Atendimento Escolar ao Aluno Afetado pela Distrofia apresentam, isto é, mesmo alunos com pouco ou nenhum movimento suficiente para a produção de atividades escritas acreditam que aulas devem ser pautadas nessa modalidade. Na concepção de muitos deles, uma aula produtiva, uma aula em que se aprende bastante é aquela que rende muito material escrito. Deste modo, temos de trazer à tona e revalorizar, junto a nossos alunos, o lugar da oralidade em sala de aula.

Nosso intuito, evidentemente, não é defender o banimento da escrita na escola, nas aulas em geral, mas chama-nos a atenção essa marca tão latente da cultura escolar inclusive em nosso público-alvo. Dito de outro modo, gostaríamos de enfatizar que a representação de que estudar e aprender são ações que se consolidam essencialmente pela escrita, nesse caso, partiu de uma grande quantidade de alunos que não tem movimento físico suficiente para tal.

Levando tal fato em consideração e tomando como premissa a questão de que muitos alunos afetados pela distrofia muscular não conseguem escrever, em função da perda de movimentos, além de parcela expressiva apresentar comprometimento intelectual que impacta diretamente habilidades atreladas ao domínio verbal, o trabalho com a oralidade se inicia como uma resposta para a demanda de garantia da produção, veiculação e apropriação de saberes junto a esses alunos.

O espaço que buscamos dedicar à oralidade é, portanto, uma necessidade no cenário em que atuamos e é também fruto do intento de dialogar com aquilo que se preconiza na formação de professores da área de Letras na contemporaneidade. Isto é, espera-se que esse 
sujeito seja alguém que busca mediar a aprendizagem de seus alunos por meio da problematização, investigação e reflexão sobre a própria prática levando-se em conta as matrizes da sua área de formação inicial.

Como ponto de partida, tomamos como cerne o debate sobre a oralidade e a escrita compreendendo-as como modalidades da língua. Seus usos se interpenetram, muitas vezes, em um continuum e a principal característica é que sua existência é permeada pelas práticas sociais e seus usos, como defende, por exemplo, Marcuschi (1997). Tomando como cerne a realidade sociocomunicativa de cada indivíduo e assumindo como objeto de estudo os usos da linguagem, e não somente seus códigos, Marcuschi apresenta um contribuição importante para repensarmos o papel da oralidade em nosso cotiano.

“(...) sob o ponto de vista mais central da realidade humana, seria

possivel

definir o homem como um ser que fala, mas não como um ser que escreve, $o$ que traduz a convicção, hoje tão generalizada quanto trivial, de que a escrita é derivada e a fala primária. Não necessária muita genialidade para constatar que todos os povos, indistintamente, têm ou tiveram uma tradição oral, mas poucos tiverem ou t $\sim$ em uma tradição escrita."(MARCUSCHI,1995, p.120)

A fim de ilustrar o argumento apresentado acima, compartilhamos uma situação vivenciada recentemente no Programa de Atendimento Escolar ao Aluno da Abdim. V.S.A ${ }^{4}$ iniciou tratamento na Associação de Assistência à Criança Deficiente em agosto de 2013 e manifestou interesse em estudar em tal local. Após ter tido aulas individuais com os professores de todas as áreas do conhecimento (Linguagens, Matemática, Ciências Humanas e Ciências da Natureza), a coordenadora do Programa foi conversar com a mãe de V.S.A para

\footnotetext{
${ }^{4}$ Siglas do nome de aluno, a fim de garantir seu anônimato. V.S.A tem 13 anos, estudou apenas até a $5^{\text {a }}$ série, com histórico de uma reprovação em função da família ter mudado de estado e não ter conseguido vaga; abandonou a escola, segundo a mãe, porque moram apenas os dois em uma casa com escadas. A mãe tem que carregar o filho, em uma cadeira de rodas enorme, por aproximadamente 25 degraus. Por essa razão, o filho só sai de casa por questões relacionadas ao tratamento.
} 
saber um pouco mais sobre suas impressões e/ou comentários que ele estava fazendo das aulas, o que havia gostado ou não, se havia planos para uma matrícula em escola regular a partir da mediação do grupo de educadores, enfim, esperava-se um primeiro feedback e a resposta da foi a seguinte " $V$. está gostando muito de poder estudar aqui, está muito animado, diz que os professores são legais e que o lugar também, mas ele tá ansioso mesmo é para ter aula porque até agora foram só conversas com os professores"

Acreditamos, conforme apresentamos anteriormente, que esse tipo de interpretação do papel da oralidade na aula é tributário do entendimento de que aula e ambiente escolar são elementos inseparáveis da proposição de atividades escritas aos alunos e que esta modalidade da língua tem um papel protagonista, sobretudo, no que diz respeito ao meio de produção e de consolidação do conhecimento.

Diante disso, levamos em conta a importância da oralidade não permanecer alijada da cultura escolar, ao contrário disso, almeja-se que seja posta também recurso potencializador da produção e veiculação de conhecimento ao longo das aulas de Linguagem e Literatura. Com isso, almeja-se garantir seu espaço no âmbito escolar sem perder de vista que essa modalidade da língua é o elo central da prática/inserção social de muitos dos alunos reais das escolas brasileiras, assimo como o é, por exemplo, do aluno que ora tomamos como cerne para esta reflexão.

Assim, se tomamos como base o dia a dia do aluno RLR, que conforme ressaltamos ainda não foi alfabetizado, sua prática social está predominantemente imersa na fala, embora bastante sucinta, uma vez que sua interação sociocomunicativa está circunscrita a esfera dos tratamentos médicos a que é submetido, pelo menos duas vezes por semana (na AACDAbdim), e ao ambiente caracterizado pelo abrigo onde vive.

Posto isto, a revalorização da oralidade, por meio de seu emprego nas aulas, ressignifica e possibilita o uso da voz para produção, reflexão e construção de conhecimento, colocando-a como elemento favorável e fundamental ao ensino - aprendizagem. É importante ressaltar que, e ainda mais porque estamos privilegiando a Literatura manifesta por meio de poéticas orais, a própria problematização do conceito e alcances do ensino de literatura se fazem necessárias.

Nessa perspectiva, destacamos Todorov, em seu livro Literatura em Perigo, que traz à tona uma reflexão bastante inspiradora sobre, de certa forma, o sentido profundo, subjetivo e, quiçá, inerente da literatura, ou seja, elementos que perpassam a experiência e motivação de 
quem, por exemplo, escolhe determinada produção literária e não outra.

A literatura pode muito. (...) tem um papel vital a cumprir; mas por isso é preciso tomá-la no sentido amplo e intenso que prevaleceu na Europa do século XIX e que hoje é marginalizado (...). O leitor comum, que continua a procurar nas obras que lê aquilo que pode dar sentido à sua vida (...). A realidade que a literatura aspira compreender é, simplesmente, a experiência humana. (TODOROV, 2010, p.76).

Embora no trecho citado Todorov use o termo "lê" e "leitor", trazemo-los à tona para intentar compreender um tanto mais nosso próprio objeto. Destarte, buscamos compreender ler e leitor como interlocutor, nessa perspectiva, o leitor comum poderia ser qualquer sujeito que se depara com uma manifestação calcada na palavra ou imagem ou som que pode, em alguma perspectivar, atribuir sentido à sua vida, ampliar sua experiência.

O que destacamos como central, portanto, é a mudança que determinada produção artística pode provocar na vida do indivíduo. Somam-se a essa reflexão os estudos de Márcia Abreu (2006), que também contribuem para uma ampliaçao do conceito de literatura, ampliando seus significados e seus alcances dentro dos debates acadêmicos. Uma das questões abordadas por Abreu e, absolutamente, pertinente a esse trabalho, é a ideia de que a literatura é dependente dos grupos sociais a que pertencem. Segundo a autora:

A apreciação estética não é universal: ela depende da inserção cultural
dos sujeitos. Uma obra é lida, avaliada e investida de significações
variadas por diferentes grupos culturais. (...)Nem todos, infelizmente, têm
essa sensatez. Na maior parte do tempo, o gosto estético erudito é
utilizado para avaliar o conjunto das produções(...). (ABREU, 2006, p.80)

Nesse sentido, a eleição do rap como mote para o desenvolvimento da prática pedagógica abarca todas as demandas aqui brevemente elencadas, isto é, o rompimento com a dicotomia oralidade versus escrita, valorização da oralidade, aproximação ao repertório, conhecimento prévio e interesses do aluno, ampliação do conceito de literatura, reflexão sobre a importância do professor problematizar os sentidos e objetivos do ensino de literatura, compromisso com a ampliação de repertório do aluno, entre outros.,

Posto isso, até aqui tivemos o intento de aclarar os dois grandes fundamentos norteadores para as práticas pedagógicas empreendidas, sendo, a priori, o rap tomado como manifestação poética oral legítima e a responsabilidade do professor ao selecionar, propor e 
conduzir um currículo atento às demandas de seu alunado.

\section{Traçando as pautas de ensino-aprendizagem, expondo os alcances da voz}

É a partir de todas as perspectivas desenhadas anteriormente que podemos relatar as atividades realizadas em aula e pautadas predominantemente pela oralidade. Compartilhamos, assim, um percurso em que fomos criando possibilidades para que o aluno se envolvesse, buscamos gerar um cenário onde as aulas não fossem meramente expositivas, mas dialogadas e, em muitos casos, tivemos a escrita como forma de intentar registrar parte do que vinha sendo construindo e intentando favorecer o contato do aluno com esferas variadas do contexto do letramento.p.

As considerações feitas até aqui são reafirmadas quando se coloca luz ao repertório prévio do aluno, ao gosto pessoal e ao saber que traz de outras vivências para o ambiente escolar na troca com o professor. Paulo Freire, em seu livro Pedagogia da autonomia, trata desta temática, afirmando que "ensinar não é transferir conhecimento", mas "estar aberto para construir o conhecimento" ao lado do educando, levando em consideração seus saberes e vivências até então.

\footnotetext{
Quando entro em uma sala de aula devo estar sendo um ser aberto a indagações, à curiosidade, às perguntas dos alunos, a suas inibições, um ser crítico e inquiridor, inquieto em face da tarefa que tenho - a ele ensinar não a de transferir conhecimento. É preciso insistir: este saber necessário ao professor - que ensinar não é transferir conhecimento - não apenas precisa ser apreendido por ele e pelos educandos nas suas razoes de ser - ontológica, política, ética, epistemológica, pedagógica, mas também precisa ser constantemente testemunhado, vivido. (FREIRE, 1996, p.27)
}

Como desdobramento prático dessa inspiração freireana, destacamos que o nosso aluno expressou forte desejo de trabalhar com música, destacando o rap com favoritismo dentro dessa esfera . O nosso trabalho foi usufruir do material que o próprio aluno nos deu, empregando-o nas aulas de Linguagens a fim de explorar a riqueza do conteúdo trazido - tão apropriado para a disciplina.

É preciso ter considerar que o objetivo norteador dos trabalhos realizados em sala de aula foi incidem na produção de um CD artesanal. Assim, esperava-se que o aluno pudesse ter, ao mesmo tempo, contato com noções de confecção independente, com o universo da cultura letrada, com prática discursiva, com sonoridade (ritmo e rima), noção de autoria e 
performance. Para tanto, nem todas as aula foram centradas na elaboração do $\mathrm{CD}$, algumas foram dedicadas ao debate sobre os conteúdos circunscritos ao movimento Hip-hop.

Nesse sentido, todas as atividades da área de Linguagem, tomando como base um conjunto de aulas produzidas entre abril/2013 e setembro/2013, foram embaladas pelo "ritmo e a poesia" do "canto-falado" produzido pelo movimento Hip-hop. Nesse ínterim, partiremos para uma parte mais expositiva, na qual se centrará a demanda e o alcance de aulas selecionadas do corpus ora mencionado.

Práticas em aula:

1. Abordagem da narrativa da vida dos jovens de periferia, como na música "To ouvindo alguém me chamar" do grupo Racionais, a fim de entender, em conjunto com a a ideia de sequência narrativa, as circunstâncias sociais e motivacionais para o crime em um contexto de periferia.

2. Entender o uso do discurso como uma forma de expressão, seja de sentimentos ou de ideologia. Para tanto, tomou-se como eixo disparador o contato com a música "Versículo 4, capítulo 3", também do grupo Racionais. O mote da aula foi o verso: “(...)minha palavra vale um tiro e eu tenho muita munição(...)” e a reflexão encadeada incidiu em elementos motivadores da manifestação artística por meio do rap, bem como as esferas de circulação que comportam tal produção.

3. Trabalhar a noção de contexto histórico, permitindo a explanação do nascimento do movimento Hip-hop, tanto nos EUA (na década de70) quanto no Brasil (na década de 80), permitindo-nos o debate sobre a nova postura de alguns MCs frente à ideologia da ostentação e da riqueza, fato queque gerou muitas letras de protesto, mas que atualmente tem sido elemento de aspiração de uma grande parte dos rappers, como já abordou FERNANDES em seus estudos. Em relação a esse propósito, destacamos a constatação do pesquisador de que "Não é demais assinalar que vários rappers e mcs são assimilados pela própria incoerência do mundo capitalista, à medida que o protesto transforma-se no culto a relógios, tênis e roupas de grife (...)”.

Nesse contexto, buscamos desenvolver a habilidade de comparar, usando como personagens os rappers Sabotage e Emicida, representantes das chamadas velha (old generation) e nova escola (new generation). O objetivo da atividade foi pensar as nuances que o passar do tempo imprime nas letras, na performance, no público, na ideologia desta produção artística. 
4. Analisar a performance, centrada no estilo(vestuário), na entonação, nos gestos e expressões faciais dos rappers, o que confere credibilidade ao que está sendo veiculado por meio da voz. Como exemplo, observemos o seguinte trecho da letra de "Marighella - Mil faces de um homem leal", música recente dos Racionais Mcs abordada em aula:

Chegou, salve geral da mansão dos bamba, não se faz revolução sem uma fuga na mão, sem justiça não há paz, há escravidão...

Revolução no Brasil tem um nome... (Marighella) a postos para o seu general.

mil faces de um homem leal. (MANO BROWN/2013)

Tal letra, sem as entonações, os gestos e as expressões faciais, não teria a mesma força ideológica, nem a mesma credibilidade veiculada através da performance de Mano Brown ao cantar, como podemos perceber pela exibição dos videoclipe em aula.

5. Produzir um CD implica o uso da voz para veicular uma ideia, ou seja, o uso da voz como discurso efetivo, bem como a noção de autoria. Também aprimora competências como a capacidade de relacionar e escolher, como o fez o aluno ao escolher uma imagem para a capa, um "nome artístico" e nesse momento se preocupar com a força sonora que o nome tinha ao ser falado, e a elaboração de seus próprios versos rimados, nascidos completamente da fala.

Todas essas questões figuram como mote para o nosso objetivo principal, isto é, estabelecer uma via de acesso para a inserção da linguagem poética. Nesse caso, os primeiros contatos com a Literatura, estruturam-se em um encontro com uma poética oral já conhecida pelo aluno. A ideia de produção de um CD independente e, consequentemente, a valorização da oralidade, uma vez que a construção do conhecimento está pautada plenamente no uso da voz foram a tônica que permitiram a esse jovem com uma trajetória marcada por tantas adversidades expressar-se, criar, compor, comparar, emitir valorações, enfim, ampliar seu repertório.

Os alcances desse conjunto de aulas remetem a ampliação da expressividade de RLR nas aulas e, em certo sentido, no empoderamento dessa sua expressão, que passa a ser plena 
de sentido, de certo modo, surpreendente, como podemos constatar a partir da transcrição de algumas de suas falas durante as aulas:

"Eu tô rimando... Eu tô fazendo poesia, né?"

"Eu tô fazendo rap? Mas eu nem sei escrever..."

"Mas por que tem que escrever? Pra não esquecer, né?"

Por meio do registro exposto acima, podemos ressaltar o emprego da oralidade, bem como sua revalorização no processo de criação artística do aluno. Ele mesmo nos deixa pistas sobre a uma primeira assimilação empreendida acerca do caráter temporal dos modos de interação com a linguagem, em outras palavras, ele emite uma valorização que coloca o oral no campo do mais efêmero, momentâneo e mais sensivelmente sujeito a variações de acordo com o interlocutor, ao passo que a escrita seria algo que conferiria permanência, durabilidade, daí a preocupação em "escrever para não esquecer".

Sua experiência pessoal, marcada pelo comprometimento no campo da memória de curto prazo e no domínio verbal é, quiçá, uma outra faceta que entra em jogo quando se pensa em recursos para não se esquecer. . Aqui cabe relembrarmos a peculiaridade do aluno RLR, bem como o grupo de alunos atendidos pelo Programa de Escolarização da Abdim, que ainda não está alfabetizado e portanto, não tem o domínio da escrita e leitura formal. Nesse sentido, as aulas de Literatura assumiram como demanda a ampliação do horizonte do aluno, utilizando seus próprios interesses, repertórios e curiosidades, além de revelar facetas inerentes ao contexto do letramento.

Assim, no caso das aulas mencionadas, a escolha pelas poéticas orais se deu também como uma resposta aos desafios que se impuseram em um meio educacional onde a oralidade é, muitas vezes, a alternativa mais satisfatória para a garantia da produção e apropriação de saberes levando-se em conta a peculiaridade de muitos alunos, inclusive daqueles que não tem movimento suficiente para produção escrita. Quiça, não seja forçoso ressaltar também que o encontro com as poéticas orais, além de alternativa fundamental tem sido mote para o estabelecimento de relação e mediação entre professor-aluno das mais prazerosas, desse moto, retomamos a base etimológica do saber e sabor, ingredientes que consideramos indispensáveis

\footnotetext{
5 Material das gravações de aula - acervo de relatório de aulas Abdim.
} 
a toda prática pedagógica.

\section{Referências bibliográficas}

ABREU, Márcia. Cultura letrada: literatura e leitura. São Paulo: Editora UNESP, 2006.

ARENDT, H. "A crise na educação", In: Entre o passado e o futuro. São Paulo: Perspectiva, 2009, p. 221-240

BRASIL. Secretária de Educação Fundamental. Parâmetros curriculares nacionais: linguagens, códigos e suas tecnologias. MEC/SEF, 2000. 
BENTES, A.C.; FERNANDES, F. "A poesia oral nas bordas do mundo: identidades em movimento nos videoclipes brasileiros de rap". In:LEITE, E. F.; FERNANDES, F. Oralidade e Literatura 3: outras veredas da voz. Londrina: Eduel, 2007, p. 121-138.

CASTILHO, A. T. de. A língua falada no ensino de português. São Paulo: Contexto, 2000.

FERNANDES, F. A voz e o sentido: poesia oral em sincronia. São Paulo: Unesp, 2010.

; MASSONI, A. "Hip Hop e Rap: história e manifestações orais no contexto londrinense". In: ANPUH - XXIII SIMPÓSIO NACIONAL DE HISTÓRIA - Londrina, 2005. Disponível em: http://anpuh.org/anais/wp-content/uploads/mp/pdf/ANPUH.S23.0121.pdf Acesso em: 08 out. 2013.

FREIRE, Paulo. Pedagogia da autonomia. São Paulo, 1996. Digitalizado em 2002 por Coletivo Sabotagem.

MARCUSCHI, L. A. Oralidade e escrita. Revista Signótica. Goiás, v. 9, n. 1 (1997). Disponível em: http://www.revistas.ufg.br/index.php/sig/issue/view/435 Acesso em: 10 de out. 2013.

NARDES, F.; ARAUJO, A. P. Q. C.; RIBEIRO, M. G. O retardo mental na distrofia muscular de Duchenne. J. Pediatr. (Rio J.) [online]. 2012, vol.88, n.1, pp. 6-16. ISSN 0021-7557. Disponível em: http://www.scielo.br/pdf/jped/v88n1/a03v88n01.pdf . Acesso em: 19 mai. 2013. ROSA,

TODOROV, T. A Literatura em perigo. Rio de Janeiro: Difel, 2010. 